\title{
Seismic design of tension wall-diaphragm anchorage for historical unreinforced masonry buildings
}

\author{
S. Moreira \\ Department of Civil Engineering, Pontificia Universidad Católica del Perú-PUCP, Lima, Peru \\ L.F. Ramos, D.V. Oliveira \& P.B. Lourenço \\ ISISE, Department of Civil Engineering, University of Minho, Guimarães, Portugal
}

V.S. Cóias

Monumenta Lda, Lisboa, Portugal

\begin{abstract}
The absence of appropriate structural connections is known to be one of the main factors contributing to the activation of out-of-plane mechanisms of masonry walls that can compromise the entire stability of a building. The high vulnerability of historical unreinforced masonry buildings to these types of mechanisms imposes the necessity to develop engineered strengthening solutions capable of ensuring positive wall-diaphragm anchorage to work in tension. A design methodology was developed covering aspects related to the estimation of the seismic demand and the design of a retrofit solution studied experimentally. The procedure proposed relies on the assessment of the resistant capacity associated with several possible failure modes and the estimation of the seismic demand considering the existing recommendations found on Eurocode 8 (CEN/TC 250 2010), ASCE/SEI 41-13, and NZSEE (2006).
\end{abstract}

\section{INTRODUCTION}

Ensuring the presence of effective tension walldiaphragm anchors is one of the primordial steps to be addressed when retrofitting a building, in order to enable a continuous load path and a "box-like" behavior (Lourenço et al. 2011, CEN/TC250 2010, Senaldi et al. 2014).

In spite of their recognized importance, walldiaphragm (or wall-to-floor) connections have not been subject of many experimental or numerical studies. Only recently, pullout tests have been conducted on strengthened original or representative walldiaphragm connections, in an effort to better characterize retrofit solutions that have been applied historically or for several years already (metallic straps, ties, injection anchors, etc.).

Lin \& LaFave (2012) carried out several pullout tests on strengthened connections (representative specimens with timber floor joists resting on slots open in the masonry wall), typical of pre-50s unreinforced masonry buildings (URM), to study their capacity and the influence of different parameters on the results. While the unstrengthened connection relied only on friction to resist to horizontal actions, the strengthened connection was equipped with wall anchors made of a steel strap and a threaded rod, welded together. The steel strap was nailed to the timber floor joist, by two nails, and the threaded rod was anchored on the external face of the masonry wall portion, by means of a washer and a standard hex nut. Its capacity was estimated to be between $5.8 \mathrm{kN}$ and $8.5 \mathrm{kN}$, and was associated with nails' shear off and pullout. It was also concluded that dynamic loading leads to more conservative displacements, in comparison with monotonic and quasi-static cyclic loadings, which consequently increases brittleness of behavior.

Campbell et al. (2012) discussed failure modes of wall-diaphragm connections strengthened with a similar solution as the one studied by Lin \& LaFave (2012), observed after the 2011 Christchurch earthquake. The most common failure mode was punching shear failure of masonry, followed by yielding or rupture of the connector rod, rupture at weld between connector rod and joist plate, and splitting of joist or stringer. The failure modes concerning failure of fixing at joist plate, splitting or fracture of the anchor plate, and yielding or rupture at threaded nut were not observed.

This paper focus on the results obtained from the quasi-static monotonic and cyclic tests performed on unstrengthened and strengthened wall-diaphragm specimens by Moreira et al. (2014) and proposes a methodology for the design of the tested tension wall-diaphragm anchors.

The type of wall-diaphragm connection studied consisted of a timber floor joist end nailed to a timber wall-plate, embedded in the masonry wall. The strengthening solution developed is an evolution of the 


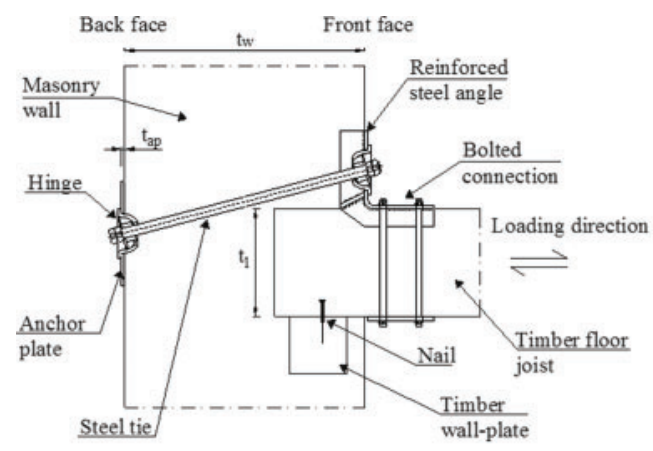

(a)

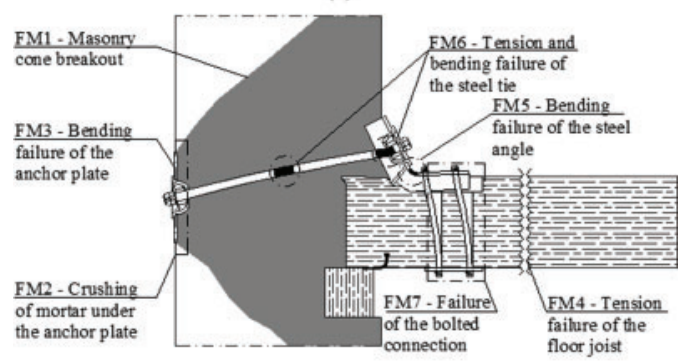

(b)

Figure 1. Example of strengthened wall-to-floor connection: (a) Configuration of the strengthening solution; and (b) possible failure modes.

metal straps being applied for centuries. It consists of a stainless steel angle bolted to the timber floor joist and anchored to the masonry wall, by means of a tie rod with an anchor plate on the exterior face of the wall (see Figure 1a). The experimental campaign enabled the characterization of failure modes, maximum pullout force, hysteretic behavior, energy dissipation, strength and stiffness degradation as well as other parameters (Moreira 2015). The different types of damages observed, which by parameter variation can become failure modes in different scenarios are presented in Figure 1b, and further developed in Section 3.

Although one is addressing retrofit design at component level, the global perspective of the building should always be taken into consideration. This means that the intervention should not decrease the overall available ductility and if clear deficiencies are detected, they should be corrected or improved as much as possible.

Previous studies pointed out that the strengthening solution under study provides high ductility to the wall-diaphragm connections, but causes a slight decrease in comparison to the unstrengthened connections. Although ductility is decreased at local level, strengthening the wall-diaphragm connections enables the formation of more ductile global failure modes that explore the in-plane capacity of walls (Moreira 2015). As part of the retrofit process, assessment of global structural performance before and after the proposed intervention, using linear or nonlinear procedures, should be considered.
The retrofit methodology contemplates various steps that go from assessment of the wall-diaphragm connection to the actual design of the retrofit solution (NZSEE 2006, ASCE/SEI-41 2014, Paganoni \& D'Ayala 2014). First phase falls into inspection and diagnose of the wall-diaphragm connection, characterizing its typology (existence of timber wall-plate, depth of the joist inside the wall, spacing between joists, etc.), the material properties (compressive and tensile strengths of masonry; density and tensile strength of timber), the existing decay (putrefaction, decreased cross-section of timber, cracks on the wall, etc.), among other aspects. This assessment can be carried out through existing information (drawings, reports, etc.), visual inspection, and semi- and/or nondestructive techniques (boroscopic camera, GPR, flatjack test, sonic tests, resistograph, etc.). Destructive testing to assess mechanical properties is rarely applicable, but when possible, constitutes a good source of information, particularly through compression and diagonal compression tests of masonry wallets, and in situ pullout tests of timber joists.

After obtaining the necessary information to proceed the assessment, one can then start the core phase of the retrofit design of the connection, which is later developed in Section 4. The next sections cover the different aspects of the design of tension wall-diaphragm anchors for historical structures.

\section{SEISMIC DEMAND}

The simplified approach proposed for the determination of the seismic demand for connections follows the steps indicated in NZS (2015), in NZSEE (2006) for parts and ASCE/SEI-41 (2014) for out-of-plane wall anchorage to diaphragms, but adapts them to the calculation philosophy adopted by the EC8 (CEN/TC 250 2010) for nonstructural elements.

All the existing recommendations consider the following variables in their formulation, in spite of the different designations:

- Seismic coefficient;

- Weight of the wall tributary to the anchor;

- Importance factor

- Behavior factor

- Factor to account for the variation of the position of the connection in height

The calculation of the horizontal seismic force, acting at the center of mass of the connection, $F_{c h, d}$, adopts the formulation considered for the horizontal seismic force of nonstructural elements, as expressed in EC8 (CEN/TC 250 2010) and it is represented by Equation 1.

$F_{c h, d}=\frac{\left(S_{c h} \cdot W_{c} \cdot \gamma_{c}\right)}{q_{c}}$

where $F_{c h, d}$ was previously defined; $S_{c h}=$ seismic coefficient applicable to connections; $W_{c}=$ weight of the wall tributary to the connection; $\gamma_{c}=$ importance 
factor; and $q_{c}=$ behavior factor of the connection. The value taken for $\gamma_{c}$ should not be inferior to the importance factor of the structure. The behavior factor, $q_{c}$, should be determined experimentally and its value should be at most 2 (CEN/TC250 2010, NZS 2015). Two horizontal seismic forces should be computed for each part of the wall tributary to the connection (above and below).

The seismic coefficient $S_{c h}$ corresponds to the minimum of two coefficients (see Equation 2), being the first relative to the spectral acceleration, $S_{c h, 1}$, and the second one concerning a rocking mechanism of the wall, $S_{c h, 2}$.

$S_{c h}=\min \left(S_{c h, 1} ; S_{c h, 2}\right)$

The coefficient $S_{c h, 1}$ is determined considering the spectral acceleration of a rigid structure affected by amplification factors, compiled in the third factor of Equation (3). The amplification factors that reflect the influence of the period of the connection and also its height relatively to the total height of the building. Since $T_{c}$ is quite difficult to estimate, one can assume that it is the same as $T_{1}$ (rigid connection to the structure), transforming Equation 3 to a much simpler one, as shown in Equation 4.

$S_{c h, 1}=\alpha \cdot S \cdot\left[\frac{3\left(1+\frac{Z}{H}\right)}{\left(1+\left(1-\frac{T_{c}}{T_{1}}\right)^{2}\right)}-0.5\right] \geq \alpha \cdot S$

$S_{c h, 1}=\alpha \cdot S \cdot\left[3\left(1+\frac{z}{H}\right)-0.5\right] \geq \alpha \cdot S$

where $\mathrm{S}_{c h, 1}$ was previously defined; $\alpha=$ ratio of the design ground acceleration on type A ground, $a_{g}$, to the acceleration of gravity; $S=$ soil factor; $T_{c}=$ fundamental vibration period of the connection; $T_{1}=$ fundamental vibration period of the buildings in the relevant direction; $z=$ height of the connection above the level of application of the seismic action (foundation or top of a rigid basement); and $H=$ building height measured from the foundation or from the top of a rigid basement. The value of the seismic coefficient $S_{c h, 1}$ may not be taken less than $\alpha \cdot S$ (CEN/TC 250 2010).

The calculation of $S_{c h, 2}$ follows the exact formulation presented in NZSEE (2006), which corresponds to the seismic coefficient capable of causing a rocking mechanism of the wall, forming a three hinges on the wall between floors, one at the level of each floor and another one at the mid-height. Its calculation is obtained through the application of the Virtual Work Principle.

\section{RESISTANT CAPACITIES}

\subsection{Masonry cone breakout (FM1)}

The principles regarding plasticity theories valid for the masonry cone breakout of headed anchors were

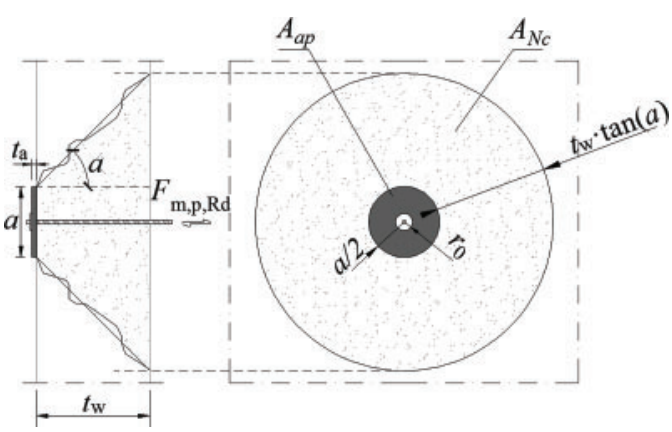

Figure 2. Projection of masonry cone breakout.

extended for tie rods with anchor plates (ACI 530 2005, CEB 1994). The design resistant capacity associated with masonry cone breakout, $F_{m, p, R d}$, can be determined according to Equation 5, which idealizes the design tensile stress, $f_{t d}$, distributed uniformly on the projected area of a $45^{\circ}$ angle stress cone radiating from the free end of the anchor plate towards the loaded end (Farrow \& Klingner 1995), as shown in Figure 2.

$F_{m, p, R d}=A_{N c} \cdot f_{t d}=\pi\left[t_{w}+\frac{a}{2}\right]^{2} \times f_{t d}$

where $F_{m, p, R d}$ and $f_{t d}$ were previously defined; $A_{N_{c}}=$ projected area of a single or group anchor; $t_{w}=$ thickness of the wall; and $a=$ diameter of the anchor plate.

Proximity between anchors and/or to the edges of the wall can cause reduction of the resistant capacity due to intersection of cone stresses or reduced size, respectively. Therefore, to prevent this reduction at least a spacing, $s$, of $2\left(t_{w}+a / 2\right)$ should be maintained.

\subsection{Mortar crushing (FM2)}

From the damage survey performed during the experimental campaign, no cracks were observed on the back face of the masonry wall, but there were small cracks on the layer of the fast-curing mortar, placed between the anchor plate and the masonry wall. This new layer of mortar had as main functions to accommodate small deformations between the anchor plate and the masonry wall, having higher compressive strength and elastic modulus than the masonry, and provide a larger area to distribute the loads to the wall. Therefore, Equation 6 allows the estimation of the design resistant capacity associated with crushing of the new layer of mortar under the anchor plate, $F_{m o, c, R d}$.

$$
F_{m o, c, R d}=A_{a p} \cdot f_{c m o d}=\pi\left(\frac{a}{2}-r_{0}\right)^{2} \cdot f_{c m o d}
$$

where $F_{m o, c, R d}$ and $a$ were previously defined; $A_{a p}=$ area of the anchor plate; $f_{\text {mod }}=$ compressive strength of the mortar; and $r_{0}=$ radius of the central hole of the anchor plate (see Figure 2).

In current applications, the fast-curing mortar can be substituted by a reinforced layer of mortar, as long 
as its area is wide enough to distribute stresses to the wall without causing permanent damage.

\subsection{Failure of the anchor plate by bending (FM3)}

For one set of tests performed during the experimental campaign, bending of the anchor plate was observed, which decreased the contact area with the masonry wall, and consequently caused a reduction of the stress cone considered for FM1. This was due to insufficient anchor plate thickness, $t_{a p}$.

The design resistant capacity associated with failure of the anchor plate by bending, $F_{a p, b, R d}$, is calculated according to Equation 7, which is based on the elastic theory of thin circular plates developed by Timoshenko \& Woinowsky-Krieger (1959).

$F_{a p, b, R d}=\frac{4 \cdot t_{a p}^{2} \cdot f_{y d}}{k \cdot a^{2}} \cdot \pi\left(\frac{a}{2}-r_{0}\right)^{2}$

where $F_{a p, b, R d}, t_{a p}, a$ and $r_{0}$ were previously defined; fyd $=$ design yield strength of the anchor plate; and $\mathrm{k}=$ factor dependent on the ratio $a / 2 r_{0}$. The value of $r_{o}$ is constant, while a can be subjected to variation.

\subsection{Tension failure of the floor joist (FM4)}

The design resistant capacity associated with tension failure of the floor joist, Ft,to, Rd, is determined assuming a uniform distributed tensile stress over the entire cross-section of the timber joist, as presented in Equation 8 (CEN/TC 250/SC5 2004).

$F_{t, t 0, \mathrm{R} d}=A_{j} \cdot f_{t, 0, d}=b \cdot \mathrm{h} \cdot f_{t, 0, d}$

where $F_{t, t 0, R d}$ was previously defined; $A_{j}=$ crosssection of the timber floor joist; $b=$ width of the floor joist cross-section; $h=$ height of the floor joist crosssection; and $f_{t, 0, d}=$ design tensile strength along the grain.

\subsection{Failure of the steel angle by bending (FM5)}

The design capacity associated with failure of the steel angle by bending, $F_{s a, b, R d}$, is difficult to predict, since the geometry of the critical section is complex and there are several geometrical and material nonlinearities associated.

The value of $59 \mathrm{kN}$ for $F_{s a, b, R d}$ was obtained from the experimental results, of the specific type of steel angle under study (Moreira 2015), which can aid ponder other values for different types of steel angles. This constitutes a major point of future research, to be studied experimentally or numerically.

\subsection{Tension and bending failure of the steel tie (FM6)}

From the damage observed on tested steel ties, it was possible to detect that it was concentrated on the section in contact with the half-spherical hinge, placed on the steel angle. That section in particular is subjected to an axial force and a bending moment transmitted by the steel angle, which decreases the maximum pullout force to be sustained by the steel tie. It was possible to estimate that this effect decreases the direct tensile strength in approximately $20 \%$, therefore Equation 9 reflects this reduction.

$F_{s t, t+b, R d}=A_{s} \cdot 0.8 f_{y d}=0.2 \pi d_{t}^{2} \cdot f_{y d}$

where $F_{s t, t+b, R d}$ was previously defined; $A_{s}=$ nominal area of the steel tie; $f_{y d}=$ design yield strength of the steel tie; and $d_{t}=$ diameter of the tie.

\subsection{Failure of the bolted connection (FM7)}

The strength capacity of the bolted connection between joist and steel angle was determined according to Johansen's theory (Johansen 1949), which is the base of the EC5 method (CEN/TC 250/SC5 2004) for design of connections with metal fasteners. The effective design load-carrying capacity of the connection, $F_{v, e f, R d}$, is the minimum capacity of all failure modes possible and can be calculated according to Equation(. Since it is a timber-to-steel single shear connection, the possible failure modes are six, and they depend on the main following variables: (1) diameter of the bolt, $d$; (2) penetration depth, $t_{1}$; (3) embedment strength in timber, $f_{h, 0, k} ;(4)$ bolt yield moment, $M_{y, R k}$; (5) axial withdrawal capacity of the bolt, $F_{a x, R k}$; and (6) position and distance between bolts in the grain direction, $a_{1}$.

$F_{v, e f, R d}=n_{\text {row }} n_{e f} F_{v, R d}$

where $F_{v, e f, R d}$ was previously defined; $n_{\text {row }}=$ number of rows of bolts; $n_{e f}=$ effective number of bolts in the row; and $F_{v, R d}=$ design load-carrying capacity of each bolt parallel to the grain.

The steel angle's leg is $6 \mathrm{~mm}$ thick (fixed dimension by manufacturer). If this dimension is in the interval between a half and a whole diameter of the bolts, the load-carrying capacity of the connection has to be interpolated from values obtained for connections with thin (equal to or less than half diameter) and thick (equal to or greater than whole diameter) steel plates.

For this type of strengthening, due to the angle of execution of the tie and the eccentricity between the shear plane of the bolted connection and the hinge, the shear behavior of the bolted connection has a beneficial contribution of a "lever" effect on the bolts caused by rotation of the steel angle. EC 5 - Section 8 (CEN/TC 250/SC5 2004) considers a similar effect in the quantification of the shear stress - the rope effect which is reflected on the parameter $F_{a x, R k}$, but contrary to this code, in this case, its contribution to the overall capacity is not limited to certain percentages. This contribution reflects the tensile strength of the bolts, and the bearing strength of the timber under the plate 
on the opposite side of the timber element, as shown in Equation 11.

$F_{a x, R k}=\min \left\{\begin{array}{c}n_{\text {row }} \cdot n \cdot \frac{\pi d^{2}}{4} \cdot f_{y k} \\ A_{\text {pi,net }} \cdot f_{c, 90, \mathrm{k}}\end{array}\right.$

where $F_{a x, R k}$ and $n_{\text {row }}$ were previously defined; $n=$ total number of bolts; $f_{y k}=$ characteristic yield strength of the bolts; $A_{p i n e t}=$ area of the plate opposing the steel angle, below the timber joist; and $f_{c, 90, k}=$ characteristic compressive strength perpendicular to the grain.

\section{DESIGN SEQUENCE}

The design sequence proposed to the tension walldiaphragm anchors is presented in 5 and initiates with the calculation of the seismic demand on the connection per meter, $F_{c h, d}$. The next step concerns the verification of the necessity to retrofit or not, by using Equation 11. If true, the unstrengthened connection has enough capacity to resist the seismic demand and there is no need to retrofit.

$\frac{F_{\text {urc }, R d}}{s_{j}} \geq F_{c h, d}$

where $F_{c h, d}$ was defined previously; $F_{u r c, R d}=$ design resistant capacity of the unstrengthened connection; and $s_{j}=$ spacing between joists.

Considering the existing literature and the pullout tests carried out on unstrengthened specimens, the design capacity of unstrengthened wall-diaphragm connections, $F_{\text {urc }, R d}$, can take values between $2 \mathrm{kN}$ and $4 \mathrm{kN}$, depending on its configuration (Cóias e Silva 2007, Moreira et al. 2012, Lin \& LaFave 2012).

If retrofit is proven to be necessary, one proceeds on the flowchart to the design of the different components of the strengthening solution. Two key aspects of the design sequence are: to consider that the distinct failure modes occur isolated and in series, which is a simplified view of the overall performance of the connections, and to establish that each of the design resistant capacities must be higher than the design seismic demand.

Using the formulae presented in Section 3, it is possible to proceed with the design of certain geometric variables, as shown in Figure 3. It goes without saying that these dimensions should be pondered within reasonable values, aiming at optimization of resources and design. The mechanical properties of the stainless steel that constitute the different components of the strengthening solution are considered fixed, therefore they are not design variables. The values of $F_{s a, b, R d}$ are assumed to be provided by the manufacturer of the steel angle (research under development). Only the resistant capacities associated with failure modes FM4 and FM5 are subjected to verification instead of design. While the latter can be iteratively adjusted, the first, if not verified, terminates the flowchart, since implicates major changes to the timber joist.

The minimum amount of anchors, $n$, and spacing between them, $s$, are obtained considering that the seismic demand is equally distributed through all the length of the wall. It is recommended to first determine $s$, which is at most equal to $F_{c, R d}$ divided by $F_{c h, d}$, taking into consideration the value of $s_{j}$. Then, one determines $\mathrm{n}$. If $\mathrm{s}$ is higher than $s_{j}, F_{c, R d}$ should be increased.

Tomaževiè (1999) suggests that $s$ should be around $1.5 \mathrm{~m}$ to $2.0 \mathrm{~m}$, while in older applications of strengthening, as for example with metal straps, this distance was approximately $4 \mathrm{~m}$. ASCE/SEI-41 (2014) considerers that the spacing between anchors should not be higher than $2.4 \mathrm{~m}$ (converted to one decimal place of $8 \mathrm{ft}$ ).

\section{APPLICATION EXAMPLE}

The example presented here concerns a connection between the 2nd and 3rd storey of an unreinforced masonry building with timber floors, as presented in Figure 4. The ground-floor and 1st floor have both $3.0 \mathrm{~m}$ of height. In terms of materials, is considered that both masonry walls (each floor) have the same design properties, which are the following: density, $\rho_{d}$, of $2000 \mathrm{~kg} / \mathrm{m} 3$ and tensile strength of $0.10 \mathrm{MPa}$. For the floor joists, it is considered that they have the following characteristic properties: density $\rho_{k}$ of 300 , $\mathrm{f}_{c, 90, k}$ of $5.0 \mathrm{MPa}$, and $\mathrm{f}_{t, 0, m}$ of $10.0 \mathrm{MPa}$. The floor joists are spaced of $0.40 \mathrm{~m}$ and have a cross-section of $0.08 \times 0.20 \mathrm{~m}^{2}$.

The building is located in the 2.1 seismic zone, according to the National Annex of Portugal, of Eurocode 8-Part 1 (CEN/TC 250 2010) and belongs to the importance class number II. The soil belongs to class $\mathrm{C}$.

Considering the seismic zone and Equation 4, it is possible to determine $\mathrm{S}_{c h, 1}$ for each floor, as shown next:

$\alpha=\frac{a_{g}}{g}=\frac{a_{g r}}{g} \cdot \gamma_{1}=0.25 g \times 1=0.25 g$

Como $1 \mathrm{~m} / \mathrm{s}^{2}<a_{g}<4 \mathrm{~m} / \mathrm{s}^{2}, \quad S=1.30$

$$
\begin{array}{ll}
2^{\text {nd }} \text { storey: } & \multicolumn{1}{c}{3^{\text {rd }} \text { storey: }} \\
z=3.00 \times 2+\frac{3.00}{2} & z=3.00 \times 3+\frac{2.75}{2} \\
=7.50 \mathrm{~m} & =10.38 \mathrm{~m} \\
S_{c h, 1}=0.25 g \times 1.30 \times & S_{c h, 1}=0.25 g \times 1.30 \times \\
\left(3\left(1+\frac{7.50}{15.95}\right)-0.5\right)= & \left(3\left(1+\frac{10.38}{15.95}\right)-0.5\right)= \\
1.30 g & 1.47 g
\end{array}
$$

The calculation of $\mathrm{S}_{c h, 2}$ follows the method suggested in section 2 and found in Section 10 of the NZSEE (2006). The main steps are briefly presented next:

- 2nd storey:

$W_{p}=\frac{3.00}{2} \times 0.50 \times 2000 \times 9.81 \times 10^{-3}=14.7 \mathrm{kN} / \mathrm{m}$ 


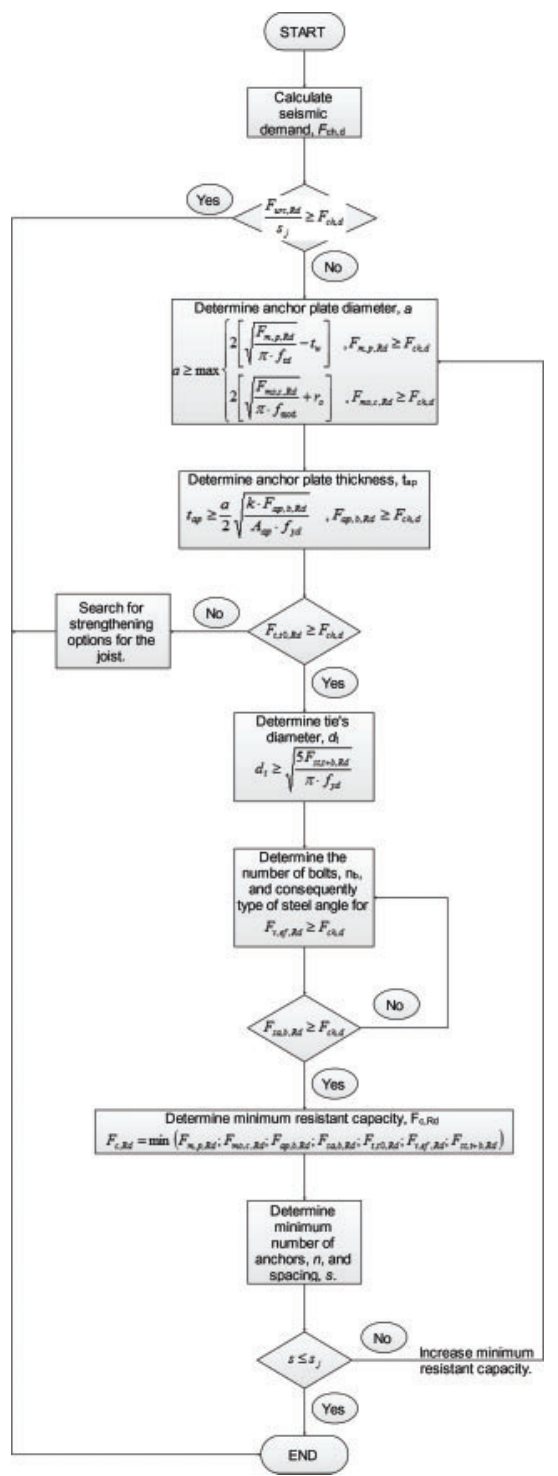

Figure 3. Design sequence of tension wall-diaphragm anchors.
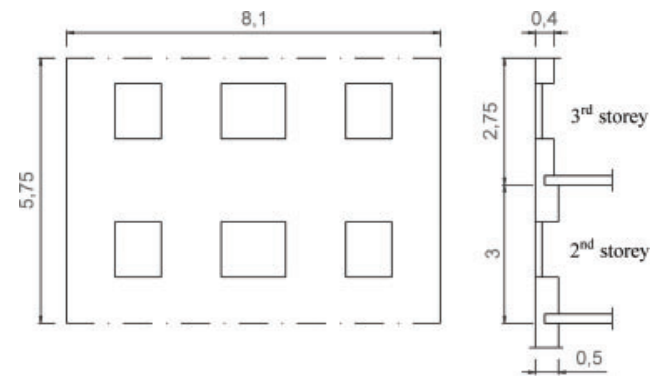

Figure 4. Representation of a connection between two floors, for exercise purposes.
For the estimation of $\mathrm{P}$ was considered a linear weight of $0.50 \mathrm{kN} / \mathrm{m}$ for the timber joist, $1 \mathrm{kN} / \mathrm{m}$ for other permanent loads, and $12 \mathrm{kN} / \mathrm{m}$ from the roof.

$$
\begin{aligned}
& P=2.75 \times 0.4 \times 2000 \times 9.81 \times 10^{-3}+1.5 \times 2 \\
& +12.0=36.6 \frac{\mathrm{kN}}{\mathrm{m}} \\
& t_{p}=\left(0.975-\frac{0.025 P}{W}\right) t_{w} \\
& =\left(0.975-\frac{0.025 \times 36.6}{2 \times 14.7}\right) \times 0.50 \\
& y_{b}=y_{t}=\frac{3.00}{4}=0.75 \mathrm{~m}
\end{aligned}
$$

The values considered for the eccentricities should be pondered according to the boundary conditions, and in this case the following were adapted.

$e_{0}=\frac{t_{p}}{2}=\frac{0.47}{2}=0.24 \mathrm{~m}$

$e_{p}=e_{t}=e_{b}=0 \mathrm{~m}$

Using the Principle of Virtual Works, one can obtain b, as follows:

$$
\begin{aligned}
b=W_{b} e_{b}+W_{t} & \left(e_{0}+e_{b}+e_{t}\right)+P\left(e_{0}+e_{b}+e_{t}+e_{p}\right) \\
& -\Psi\left(W_{b} y_{b}+W_{t} y_{t}\right) \\
& =14.7 \times 0+14.7 \times(0.24+0+0) \\
& +36.6 \times(0.24+0+0+0)-0.030 \\
& \times(14.7 \times 0.75 \times 2)=11.4 \mathrm{kN} . \mathrm{m} / \mathrm{m}
\end{aligned}
$$

The value determined for the $\mathrm{S}_{c h, 2}$ of the 2 nd floor is the one presented next:

$\delta_{c h, 2}=\frac{b}{\left(W_{b} y_{b}+W_{t} y_{t}\right)}=\frac{11.4}{2 \times 14.7 \times 0.75}=0.52 \mathrm{~g}$

For the 3rd floor, the same procedure was applied and the of $0.28 \mathrm{~g}$ was obtained for $\mathrm{S}_{c h, 2}$. The $\mathrm{S}_{c h}$ adopted for each floor is the minimum of both the coefficients, which in this case is $0.52 \mathrm{~g}$ and $0.28 \mathrm{~g}$, for the $2 \mathrm{nd}$ and 3rd floors, respectively.

The design seismic force on the connection, assuming a $\gamma_{p}$ of 1.0 and $q_{p}$ of 1.5 takes the value of $7.1 \mathrm{kN}$. The intermediate steps are:

$2^{\text {nd }}$ storey: $F_{c h, d}^{\text {Piso } 2}=\frac{S_{c h} \cdot W_{c} \cdot \gamma_{c}}{q_{c}}=\frac{0.52 \times 14.7 \times 1}{1.5}=5.1 \mathrm{kN} / \mathrm{m}$

$3^{\text {rd }}$ storey: $F_{c h, d}^{\text {Piso } 3}=\frac{S_{c h} \cdot W_{c} \cdot \gamma_{c}}{q_{c}}=\frac{0.28 \times 10.8 \times 1}{1.5}=2.0 \mathrm{kN} / \mathrm{m}$

$F_{\text {ch,total }, d}=F_{c h, d}^{\text {Piso } 2}+F_{c h, d}^{\text {Piso } 3}=5.1+2.0=7.1 \mathrm{kN} / \mathrm{m}$

Considering the spacing of $0.40 \mathrm{~m}$ and the value obtained experimentally for $\mathrm{F}_{u r c, R d}, 2.3 \mathrm{kN}$, one obtains a linear force of approximately $5.8 \mathrm{kN} / \mathrm{m}$, which is lower than $\mathrm{F}_{c h, t o t a l, d}$, meaning the connection has to be retrofitted.

Proceeding on the design sequence presented in Figure 3, the following steps regard the design of some parameters. In Table 1 are presented the design results determined for the retrofit solution and in Figure 5 is shown the distribution of the anchors on the connections. 
Table 1. Results of the design sequence.
Anchor plate diameter, $a$

Anchor plate thickness, $t_{a p}$

Ties diameter, $d_{t}$

Bolted connection

Spacing, $s$

Number of anchors, $n$
$0.25 \mathrm{~m}$

$0.006 \mathrm{~m}$

$\varphi 12$

$4 \varphi 8$

$2.40 \mathrm{~m}$

4

\section{Façade}

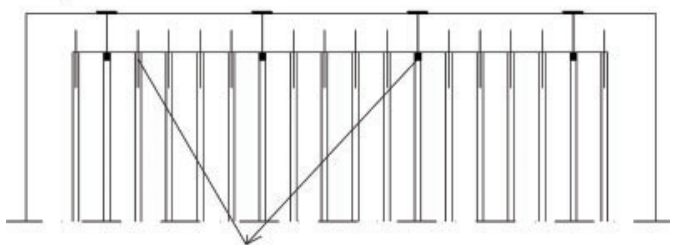

\section{Retrofitted joints}

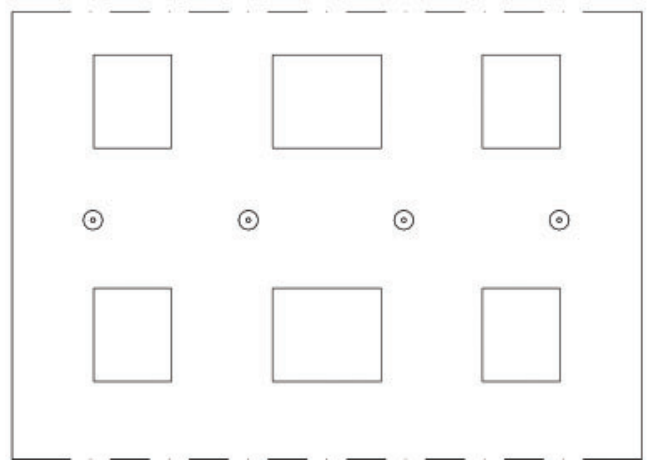

Figure 5. Distribution of the wall-diaphragm anchorage.

\section{CONCLUSIONS}

The proposed design for the tension wall-diaphragm anchorage is one more step for the integrated approach to develop an "engineered strengthening", which started with the experimental campaign on the prototypes proposed by the company Monumenta Lda.

The proposed procedure is a force-based design method and aims at assisting practitioners on implementing a simplified calculation of the tension anchors.

A quantification of the seismic demand on tension anchors for linear procedures was proposed, comparing and adapting existing recommendations found on Eurocode 8 (CEN/TC250 2010), ASCE/SEI 41-13, and NZSEE (2006) to the specificities of wall-diaphragm connections.

Based on the existing literature and the experimental results, it was possible to establish a set of possible failure modes and define their respective resistant capacities formulae, which enable accurate design of the different components of the tension anchors.
Future works contemplate, as already mentioned, experimental and numerical campaigns to characterize the behavior of the steel angle when subjected to bending, and further development of the design methodology, including application to case studies.

\section{ACKNOWLEDGEMENTS}

The authors would like to acknowledge Professor Jason Ingham for providing essential information and technical expertise concerning the NZSEE (2006) application. This work was partially funded by project FP7-ENV-2009-1-244123-NIKER of the 7th Framework Program of the European Commission, and by FCT, within ISISE, project UID/ECI/04029/2013, which are gratefully acknowledged.

\section{REFERENCES}

ACI 530, 2005. Building Code Requirements for Masonry Structures (ACI 530-05), Masonry Standars Joint Comittee.

ASCE, 2014. ASCE/SEI 41-13. Seismic Evaluation and Retrofit of Existing Buildings, USA.

Campbell, J. et al., 2012. Test results for extracted wallto-diaphragm anchors from Christchurch unreinforced masonry buildings. SESOC Journal, 25(1), pp. 57-67.

CEB, 1994. Fastenings to Concrete and Masonry Structures. State-of-the-art report, London: Thomas Telford.

CEN/TC 250, 2010. EN 1998-1: 2010 Eurocode 8 - Design of structures for earthquake resistance. Part 1: General rules, seismic actions and rules for buildings.

CEN/TC 250/SC5, 2004. EN 1995-1-1:2004. Eurocode 5 Design of timber structures - Part 1-1: General-Common rules and rules for buildings, Brussels, Belgium.

Cóias e Silva, V., 2007. Reabilitação Estrutural de Edificios Antigos, Lisboa: Argumentum.

Farrow, C.B. \& Klingner, R.E., 1995. Tensile Capacity of Anchors with Partial or Overlapping Failure Surfaces: Evaluation of Existing Formulas on an LRFD Basis. ACI Structural Journal, 92(6), pp. 698-709.

Johansen, K.W., 1949. Theory of Timber Connections. International Association of Bridge and Structural Engineering, 9, pp. 249-262.

Lin, T.J. \& LaFave, J.M., 2012. Experimental structural behavior of wall-diaphragm connections for older masonry buildings. Construction and Building Materials, 26, pp. 180-189.

Lourenço, P.B. et al., 2011. Analysis of Masonry Structures Without Box Behavior. International Journal of Architectural Heritage, 5(4-5), pp. 369-382. Available at: http://www.tandfonline.com/doi/abs/10.1080/15583058. 2010.528824.

Moreira, S. et al., 2014. Developing a seismic retrofitting solution for wall-to-floor connections of URM build-ings with wood diaphragms. In 9th International Masonry Conference (9th IMC). Guimarães, Portugal.

Moreira, S. et al., 2012. Experimental study on the seismic behavior of masonry wall-to-floor connections. In 15th World Conference on Earthquake Engineering.

Moreira, S., 2015. Seismic retrofit of masonry-to-timber connections in historical constructions. University of Minho. 
NZS, 2015. NZS 1170 . 5: 2004 Structural Design Actions Part 5: Earthquake actions - New Zealand.

NZSEE, 2006. Assessment and Improvement of the Structural Performance of Buildings in Earthquakes. Section 10 Revision Seismic Assessment of Unreinforced Masonry Buildings.

Paganoni, S. \& D'Ayala, D., 2014. Testing and design procedure for corner connections of masonry heritage buildings strengthened by metallic grouted anchors. Engineering Structures, 70, pp. 278-293.

Senaldi, I. et al., 2014. The Effect of Stiffened Floor and Roof Diaphragms on the Experimental Seismic Response of a
Full-Scale Unreinforced Stone Masonry Building. Journal of Earthquake Engineering, 18(3), pp. 407-443. Available at: http://www.tandfonline.com/doi/abs/10.1080/136 32469.2013.876946 [Accessed March 24, 2014].

Timoshenko, S. \& Woinowsky-Krieger, S., 1959. Theory of Plates and Shells Second Edi., McGraw-Hill Book Company.

Tomaževič, M., 1999. Earthquake-resistant design of masonry buildings A. S. Elnashai \& P. J. Dowling, eds., Imperial College Press. 